\title{
IgE deposition in normal skin of patients with rheumatoid arthritis in relation to clinical and laboratory findings*
}

\author{
L S DE CLERCK,$^{14} \mathrm{M} \mathrm{L} \mathrm{WESTEDT,}{ }^{1}$ A CATS, ${ }^{1}$ B J VERMEER ${ }^{2}$ \\ E F WELTEVREDEN ${ }^{3}$ C H BRIDTS, ${ }^{4}$ AND W J STEVENS ${ }^{4}$
}

From the ${ }^{1}$ Department of Rheumatology and the ${ }^{2}$ Department of Dermatology, University Hospital, Leiden, The Netherlands; the ${ }^{3}$ Department of Pathology, University of Leiden, The Netherlands; and the ${ }^{4}$ Departmento of Immunology, University of Antwerp (UIA), Belgium

SUMMARY Biopsy specimens from apparently normal skin of 28 patients with classical orत definite rheumatoid arthritis (RA) were examined for the presence of IgE deposition by a direct immunofluorescence technique. IgE deposition was found in 12 patients $(43 \%)$ and in none of the 10 controls. This deposition was mainly localised on mast cells, and in three patients perivascular IgE staining was also noted. The skin from nine of the 12 patients also showed deposition of IgM and complement $\mathrm{C} 3$ or $\mathrm{C} 4$ factor, or both. All 12 patients with skin IgED deposition had raised levels of IgM rheumatoid factor (RF) in the serum. Nine of these also hade IgE RF. IgE-containing circulating immune complexes (IgE CIC), raised serum IgE levels, and extra-articular (EA) manifestations were present in respectively 10, nine, and eight skin I I positive patients. It is suggested that IgE and IgE CIC may be involved in the pathogenesis ff RA and its EA manifestations.

Key words: IgE CIC, immunofluorescence, vasculitis.

IgE-mediated release of vasoactive amines is an important factor in the deposition of circulating immune complexes (CIC) in the vessel wall, and this can subsequently lead to vasculitis. ${ }^{1}$ Furthermore, the presence of IgE CIC is associated with extraarticular manifestations in RA. On the other hand, a good correlation has been shown between IgE deposition in apparently normal skin of RA patients, extra-articular manifestations, and disease activity. ${ }^{4}$

The present study was performed in order to look for IgE deposition in the skin of RA patients and to correlate IgE deposition with clinical and laboratory findings, especially extra-articular manifestations.

\section{Patients and methods}

PATIENTS AND CONTROLS

Thirty-nine patients with classical or definite RA according to the American Rheumatism Association

\footnotetext{
Accepted for publication 10 April 1985.

Correspondence to Dr L S De Clerck, Department of Immunology, University of Antwerp (UIA), Belgium.

* This work was presented in part at the British Society for Rheumatology, London, November 1984.
}

criteria $^{5}$ were studied. The mean age was 54 yeare $\overrightarrow{\vec{E}}$ (range 23-74 years). Thirty patients were seroposi 3 tive for IgM RF, and nine were seronegative? Special attention was paid to the presence of $E$. manifestations of RA such as skin nodules, peri@ carditis, pleuritis, lung nodules or lung fibrosis, skiß̊ vasculitis, and peripheral neuropathy.

Twenty-three patients had EA manifestations, $1 \frac{16}{6}$ had articular disease only. The activity of the disease was scored according to the Ritchie articular index. A score of more than 16 was considered as active RA. None of the RA patients studied had diseases such as asthma, rhinitis, or atopic eczema, known to be associated with increased IgE. IgE CIC levels ofs RA patients were compared with the levels obtained in 35 normal controls, 37 patients with IgE-mediate asthma, and 35 patients with chronic schistoso ${ }^{\omega}$ miasis. Details of these patients have been giver elsewhere. ${ }^{78}$ Of the 39 RA patients studied, skis punch biopsy specimens of the normal upper arn were available in $28 ; 20$ were seropositive and eight seronegative, 12 showed EA manifestations, 16 had no EA manifestations. In the biopsy group 
preselection was made in order to compare seropositive with seronegative patients and patients with EA manifestations with patients without EA manifestations. Skin biopsy specimens were also obtained from 10 healthy controls, all members of the hospital staff (without rheumatic or allergic diseases).

TOTAL SERUM I GE

Total serum IgE was determined by the Phadebas PRIST method (Pharmacia Belga, Brussels, Belgium).

I g E C I C

IgE CIC were determined as described previously. ${ }^{8}$ Briefly, $50 \mu$ l of serum was diluted 1:1 with PBS (phosphate buffered saline, Dulbecco's formula $\mathrm{pH}$ $7 \cdot 4$ ), and $100 \mu \mathrm{l} 5 \%$ polyethyleneglycol 6000 (PEG, Merck, Darmstadt) in PBS was added. After incubation for $1 \mathrm{~h}$ at $4^{\circ} \mathrm{C}$ the mixture was spun at $4^{\circ} \mathrm{C}$ at $3000 \mathrm{~g}$ for $1 \mathrm{~h}$. The precipitate was washed once with $2.5 \%$ PEG in PBS with $0.1 \%$ Tween 20 (polysorbate 20, Merck Darmstadt). $50 \mu \mathrm{l}$ antihuman ${ }^{125} \mathrm{I}-\mathrm{IgE}$ (Pharmacia Belga, Brussels) was added, and after overnight incubation at $4^{\circ} \mathrm{C} \mathrm{IgE}$ CIC were precipitated again with $2 \cdot 5 \%$ PEG in PBS with $0.1 \%$ Tween 20 . A reference curve was constructed by incubating serial dilutions of a serum containing more than $2000 \mathrm{kU} / \mathrm{l} \mathrm{IgE}$ with equine antihuman IgE (Kallestadt Laboratories, Inc, Oiaska, Minn., USA) for $1 \mathrm{~h}$ at $37^{\circ} \mathrm{C}$. Results were expressed as a percentage of the total radioactivity added, and IgE CIC were considered to be raised when they exceeded the mean $+2 \mathrm{SD}$ of controls.

\section{I g E R F}

The IgE RF was detected by an enzyme-linked immunosorbent assay. In short, microtitre wells were coated by incubation with heat-aggregated human IgG (40 mg/l in $0.1 \mathrm{M}$ carbonate/bicarbonate, $\mathrm{pH}$ 9.6) for $3 \mathrm{~h}$ at $37^{\circ} \mathrm{C}$ and then washed extensively with PBS with $0 \cdot 1 \%$ Tween 20 .

The following sequence of incubations was performed to assess the binding of IgE from patients' sera to the coated IgG: (a) Incubation with duplicate $100 \mu \mathrm{l}$ samples of test sera diluted 1:10 in PBS with $0 \cdot 1 \%$ Tween 20 containing $1 \%$ fetal calf serum (FCS) for $1 \mathrm{~h}$ at $37^{\circ} \mathrm{C}$. (b) Incubation with goat antihuman IgE diluted $1: 200$ in PBS with $0.1 \%$ Tween 20 containing $1 \%$ FCS for $1 \mathrm{~h}$ at $37^{\circ} \mathrm{C}$. The monospecificity for IgE was obtained with the technique described by Hijmans et al. ${ }^{9}$ (c) Incubation with peroxidase-conjugated rabbit antigoat IgG (Nordic, Tilburg, The Netherlands) diluted 1:1000 in PBS with $0.1 \%$ Tween 20 containing $1 \%$ FCS for $1 \mathrm{~h}$ at $37^{\circ} \mathrm{C}$. (d) Incubation with $100 \mathrm{mg} / \mathrm{l} o-$ phenylenediamine (Sigma Chemicals, St Louis,
Missouri) in $0.05 \mathrm{M}$ phosphate, $\mathrm{pH} 5 \cdot 6$, containing $0.01 \% \mathrm{H}_{2} \mathrm{O}_{2}$ for $20 \mathrm{~min}$ at room temperature.

Between the incubations the cells were washed three times with PBS with $0 \cdot 1 \%$ Tween 20 . The last incubation was stopped by the addition of 50 $\mu \mathrm{l}$ aliquots of $10 \% \mathrm{H}_{2} \mathrm{SO}_{4}$. The absorbance was measured at $492 \mathrm{~nm}$ with a Flow Titertek multiscan spectrophotometer. Sera were considered to contain IgE RF when both samples tested exceeded the mean $+2 \mathrm{SD}$ of control samples.

\section{H I S T O PATHOLOGY}

Biopsy specimens were punched from clinically normal skin on the medial side of the upper arm and snap frozen in liquid nitrogen. Duplicate specimens were fixed in $4 \%$ formaldehyde. Sections of the latter were stained with haematoxylin eosin and with toluidine blue. Infiltration of mononuclear cells or mast cells, or both, was scored by two independent observers, both unaware of the clinical condition. Infiltration of cells was scored semiquantitatively by counting the number of mononuclear cells per vessel and, for mast cells, by counting the number of mast cells in three adjacent high power fields $(\times 500)$ in the upper dermis, perpendicular to the epidermis.

IMMUNOFLUORESCENCE (IF) STUDIES

Cryostat sections (4-6 $\mu \mathrm{m}$ thick) were prepared and direct IF performed according to established methods. ${ }^{10}$ For IgE a monospecific fluorescein isothiocyanate conjugated rabbit $F(a b) 2$ anti-IgE (Centraal Laboratorium van de Bloedtransfusiedienst van het Nederlandsche Roode Kruis, Amsterdam, The Netherlands) was used. The specificity for IgE was obtained with the technique described by Hijmans et al. ${ }^{9}$ All sections were examined under a Leitz fluorescence microscope by two independent observers.

STATISTICAL ANALYSIS

Statistical analysis was performed by $\chi^{2}$ analysis with Yates's correction and regression analysis by calculation of the linear correlation coefficient.

Table 1 Number of IgE CIC positive individuals and IgE CIC serum levels

\begin{tabular}{lccc}
\hline Groups & $n$ & $\begin{array}{l}\text { No of positive } \\
\text { individuals }\end{array}$ & $\begin{array}{l}\text { IgE CIC (\% total } \\
\text { activity*) }\end{array}$ \\
\hline Normal controls & 35 & 2 & $0 \cdot 76 \pm 0 \cdot 25$ \\
Allergic asthma & 37 & 22 & $2 \cdot 80 \pm 2 \cdot 76$ \\
Schistosomiasis & 35 & 35 & $17 \cdot 64 \pm 8 \cdot 30$ \\
Rheumatoid arthritis & 39 & 26 & $9 \cdot 28 \pm 12 \cdot 80$ \\
\hline
\end{tabular}

* Mean $\pm S D$. 


\section{Results}

SERUM IgE CIC

The serum IgE CIC were raised in 26 of the $39 \mathrm{RA}$ patients, in 22 of the 37 patients with allergic asthma, and in all 35 of the schistosomiasis group (Table 1). There was a wide variation in the individual data. Serum IgE CIC levels were significantly more frequently raised in patients with EA manifestations than in those without $(p<0 \cdot 05)$. There was no good correlation between IgE CIC levels and clinical activity as measured by the Ritchie index $(\mathrm{r}=0 \cdot 27)$.

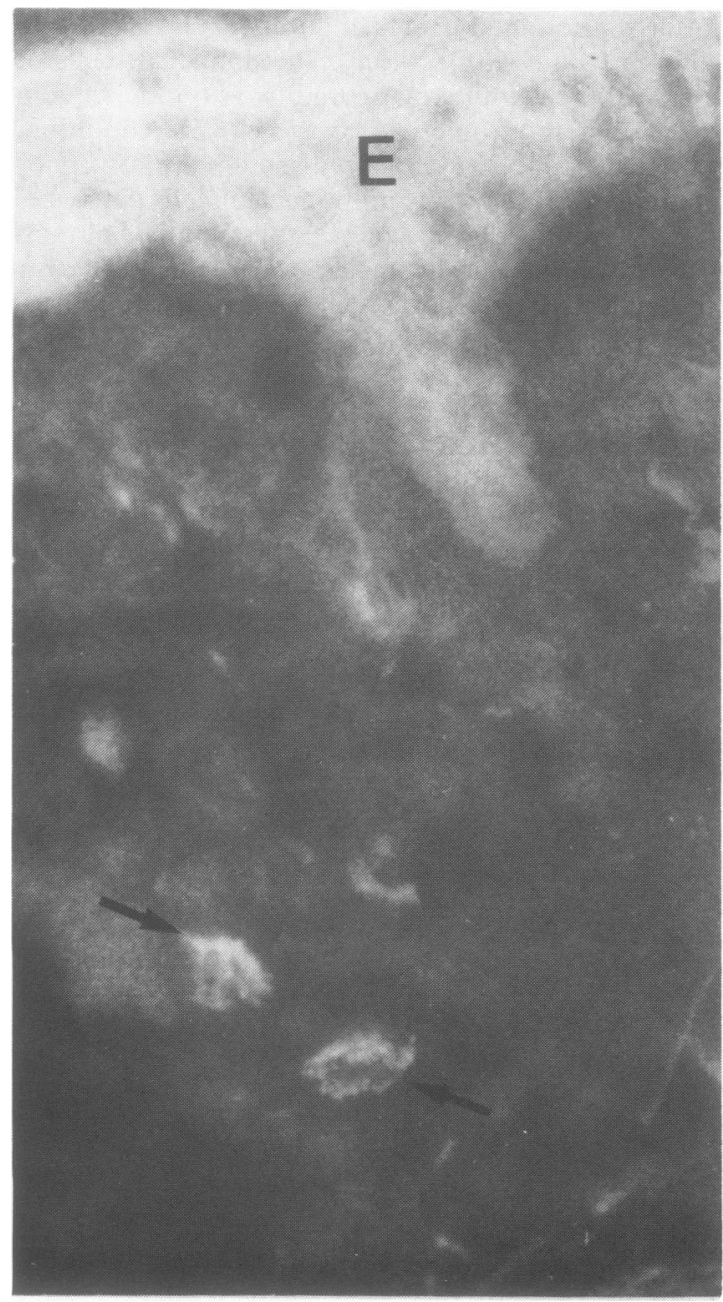

Fig. 1 Mast cell associated IgE deposition (arrows) in the upper dermis. E=epidermis. $(\times 500)$.
IgE DEPOSITION IN THE SKIN

Twelve of 28 patients $(43 \%)$ examined showe fluorescence for $\operatorname{IgE}$ clearly exceeding backgrounit: activity, whereas none of the 10 controls was positive. In all IgE positive biopsy specimens mas cell associated deposition (Fig. 1) was apparent, ang. perivascular deposition was also seen in three (Fige 2).

Other class immunoglobulin or complement de्छ position, or both was present in the biopsy specimens from $9 / 12$ skin IgE positive patients, in contrast with $3 / 16$ without IgE deposition $(p=0 \cdot 0050$ (Table 2). There was a strong correlation betwees serum IgE levels and the presence of skin Ig $\tilde{F}_{0}$ deposition. Only $3 / 12$ skin IgE positive patients had serum IgE levels $<180 \mathrm{kU} / \mathrm{l}(\mathrm{p}<0 \cdot 001)$ (Table 2$)_{\dot{n}}^{+}$ Raised IgE CIC levels were present in 10/12 skir IgE positive patients whereas $11 / 16$ skin $\operatorname{IgE}$ nega tive patients had no IgE CIC $(p=0 \cdot 01)$ (Table 2$)_{\circ}^{N}$

All patients with skin IgE deposition were posi

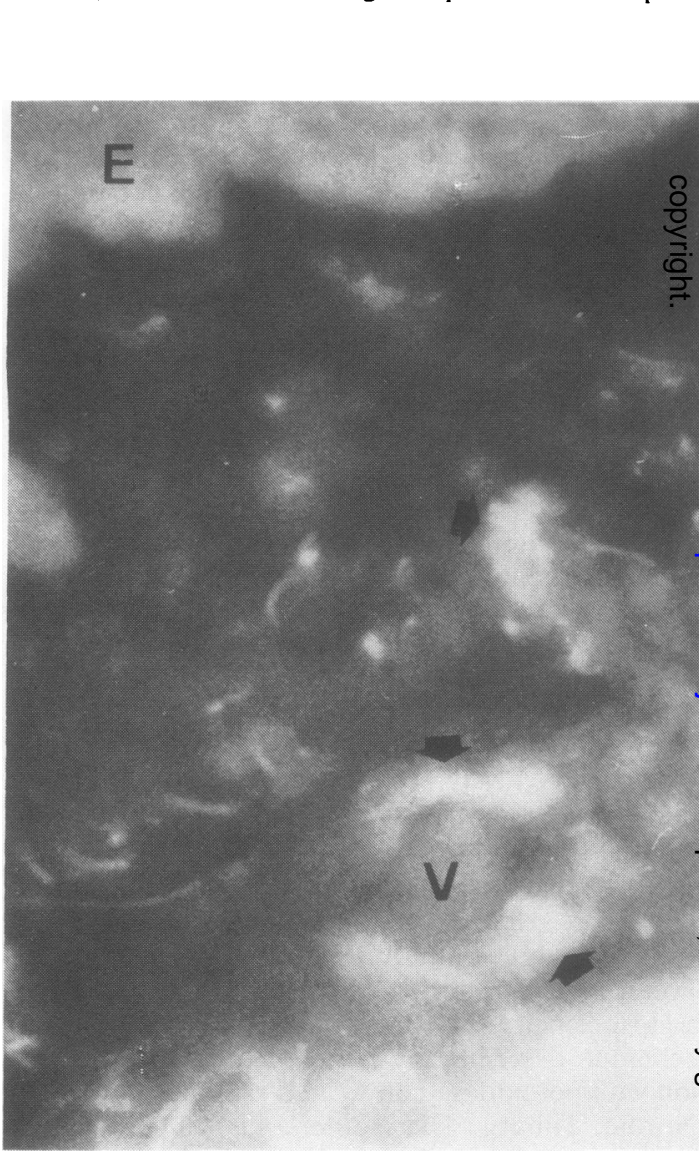

Fig. 2 Perivascular IgE deposition (arrows) around dermal vessel. $E=$ epidermis; V=vessel. $(\times 415)$. 
Table 2 Relationship between skin IgE deposition and some laboratory and clinical findings

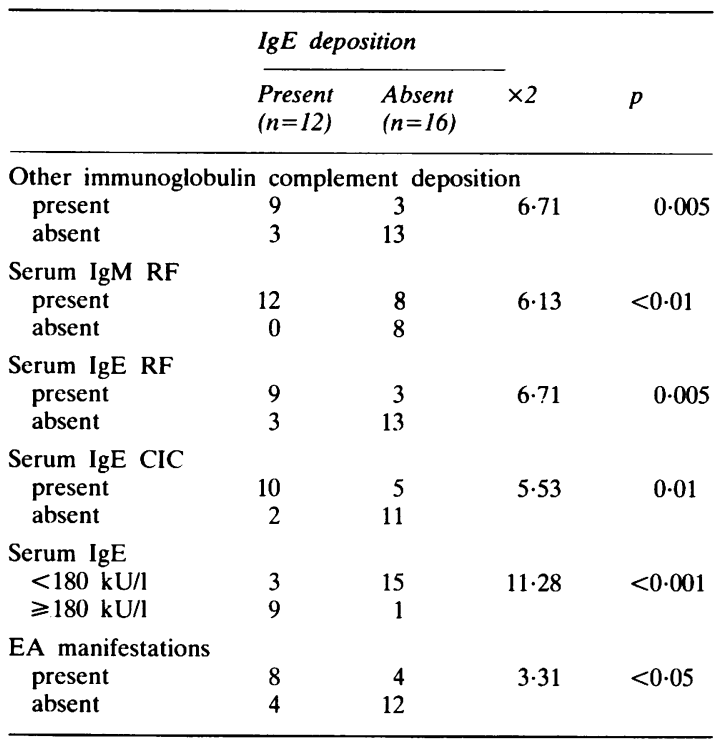

tive for IgM RF, as determined by Rose-Waaler $($ titre $\geqslant 1 / 32$ ) and latex fixation (titre $\geqslant 1 / 320$ ) tests. None of the eight seronegative patients examined had skin IgE deposition.

IgE RF was present in $9 / 12$ patients in the skin IgE positive group compared with $3 / 16$ in the skin IgE negative group $(p=0.005)$ (Table 2$)$.

There was no correlation between the presence of antinuclear factor in the serum and skin IgE deposition.

Eight out of 12 skin IgE positive patients had EA manifestations of the disease, mostly rheumatoid nodules (seven patients), one patient presented with pleuritis, one with lung fibrosis, and one with Felty's syndrome; this compares with 4/16 skin negative patients who also had EA manifestations $(\mathrm{p}<0.05)$ (Table 2).

\section{H I S T O P A T H O L O G Y}

No correlation was found between IgE deposition and the degree of mononuclear cell infiltration or the number of mast cells. With our semiquantitative measurements it was not possible to detect a significant increase in the number of mast cells in our RA patients as compared with the normal controls (mean $11 \pm 3$ mast cells per high power fields versus $8 \pm 1$ ).

\section{Discussion}

In this study we examined the possible role of IgE and IgE CIC in RA by evaluating the prevalence of IgE CIC and of IgE deposition in the most accessible microvascular organ, the skin.

Serum IgE levels were frequently raised in the RA patients and could not be explained by the presence of atopic disease, although we did not exclude the involvement of specific IgE antibodies to allergens. In this context, apart from respiratory, food, and bacterial antigens, drugs (especially gold and D-penicillamine) might also be involved. Three of the $28 \mathrm{RA}$ patients were receiving gold therapy, of these only one had raised serum IgE, IgE CIC, and skin IgE deposition.

Earlier studies on skin biopsy specimens showed a correlation between the IgE fluorescence on mast cells and the presence of atopy, but not merely between skin fluorescence and serum IgE level. ${ }^{11}{ }^{12}$ In these studies however, no patients with systemic diseases were examined.

The literature provides some evidence for the role of IgE RF in vasculitis. ${ }^{13}$ In our study IgE RF was present in 9/12 skin IgE positive patients. However, these nine patients also possessed IgM RF, so the specific role for IgE RF is not obvious. Furthermore, IgM RF has been shown to cause vascular damage in experimental animal models. ${ }^{14}$

IgE CIC were present in 26 of the $39 \mathrm{RA}$ patients studied. At the moment we do not know the composition of these CIC. In allergic asthma we have shown that allergen-specific antibodies can be found in the CIC. ${ }^{15}$ In RA IgE RF has been reported to be present in these CIC. ${ }^{2}$ Others have shown anti-IgE autoantibodies in these complexes. ${ }^{16}$ The possibility of complex formation between the IgE antibody and anti-isotypic antibody ${ }^{17}$ or anti-idiotypic antibody ${ }^{18}$ has also to be evaluated. However, whatever the antigenic composition of these CIC, it is likely that they bind to mast cell receptors for aggregated IgE. This has recently been shown by experiments in vivo where injection of IgE CIC intracutaneously into healthy subjects provoked a reversed type immediate skin reaction. ${ }^{16}$ Moreover, receptors for aggregated IgE are also present on the surface of some mononuclear cells. ${ }^{19}$

What might be the role of IgE deposition in the skin, found in $43 \%$ of the RA patients examined? IgE receptors, mainly on mast cells but probably also on the surface of some monocytes, are numerous in normal human dermis ${ }^{20}$ and may be involved in the pathogenesis of systemic disease. ${ }^{21} 22$ Thus organs rich in IgE receptors, such as lung and skin, might not only be prone to allergic manifestations, such as asthma or urticaria, but also to EA features in patients with systemic diseases, especially RA. The finding that IgE CIC were present in two thirds 
of our RA patients, especially in those with EA manifestations, might support this hypothesis.

To our knowledge this is the first report where skin biopsy specimens of RA'patients were systematically analysed for IgE deposition. In our patient group a good correlation between skin IgE deposition and EA manifestations was found. We know from earlier work that the presence of $\operatorname{IgM}$ and complement factors in the (apparently) normal skin correlates with EA manifestations in RA. ${ }^{423-26}$ In systemic lupus erythematosus the presence of IgE deposition in renal biopsy specimens was associated with a poor prognosis, ${ }^{27}$ although other reports were conflicting. ${ }^{28} 29$ There are few reports concerning IgE deposition in vasculitis lesions: Asghar $^{30}$ and Parish $^{31}$ both report IgE amongst other immunoglobulins in two patients with leucocytoclastic and mononuclear cell vasculitis respectively. Our failure to find a correlation between the number of mast cells in the skin and the presence of skin $\operatorname{IgE}$ deposition could indicate that a specific subpopulation of mast cells is involved in RA.

In conclusion, degranulation of mast cells and basophils by $\operatorname{IgE}$ and/or IgE CIC and activation of mononuclear cells by IgE CIC via specific Fc receptors might predispose to vasculitis. In order to determine a specific pathogenic significance for these IgE-related mechanisms in RA and other systemic diseases prospective studies combined with serial serum sampling and skin biopsies might lead to a better understanding. In this way questions might be answered as to whether RA patients with raised $\mathrm{IgE}$, presence of $\mathrm{IgE} \mathrm{RF}$ and/or $\mathrm{IgE} \mathrm{CIC}$, and/or skin IgE deposition are more susceptible to future development of vasculitis. The possibility that these findings are merely epiphenomena, reflecting a non-specific activation or derepression of the immune system, has to be excluded.

The authors wish to thank E De Vries, PhD and G Doekes, $\mathrm{PhD}$ for their helpful criticism and technical advice and Ms C Guerry for typing the manuscript. The goat antihuman IgE was kindly provided by Dr Radl, Institute for Experimental Gerontology, TNO, Rijswijk, The Netherlands.

\section{References}

1 Cochrane C G, Koffler D. Immune complexes disease of experimental animal and man. Adv Immunol 1973; 16: 185-264.

2 Meretey K, Falus A, Erhardt C C, Maini R N. IgE and IgErheumatoid factors in circulating immune complexes in rheumatoid arthritis. Ann Rheum Dis 1982; 41: 405-8.

3 Meretey K, Falus A, Bohm V, Permin H, Wiik A. IgE class immune complexes in Felty's syndrome: characterisation of antibody activities in isolated complexes. Ann Rheum Dis 1984; 43: 246-50.

4 Westedt M L, Meijer C J, Vermeer B J, Cats A, de Vries E. Histo- and immunopathology of the skin and relationship with some clinical parameters in patients with rheumatoid arthritis. Rheumatol 1984; 11: 448-53.

5 Ropes M W, Bennett G A, Caleb S, Jacox R, Jessar R A. 1958 . revision of diagnositc criteria for rheumatoid arthritis. But Rheum Dis 1958; 9: 175-6.

6 Ritchie D M, Boyle J A, McInnes J M. Clinical studies with a⿸丆 articular index for the assessment of joint tenderness in patiente with rheumatoid arthritis. $Q \mathrm{~J}$ Med 1968: 37: 393-406.

7 Stevens W J, Feldmeier H. Bridts C H. Daffala A A. IgG- an IgE-circulating immune complexes, total serum IgE and para site related IgE in patients with mono- or mixed infection wit w Schistosoma mansoni and/or S.haematobium. Influcnce of therapy. Clin Exp Immunol 1983; 52: 144-52.

8 Stevens W J, Bridts C H. IgG-containing and IgE-containing circulating immune complexes in patients with asthma andw rhinitis. J Allergy Clin Immunol 1984: 73: 276-82.

9 Hijmans W, Schmit H R E, Klein F. An immunofluorescenc procedure for the detection of intraccllular immunoglobulins Clin Exp Immunol 1969; 4: 457-72.

10 Herrmann W A, Kaufmann R H, Van Es L A. Daha M R $\overrightarrow{-}$ Meijer C J L M. Allergic vasculitis. Arch Dermatol Res 1980 269: $179-87$.

11 Feltkamp-Vroom T M. IgE auf mastzellen. Allergologie $1984^{\text {N }}$ 7: $20-2$.

12 Feltkamp-Vroom T M, Stallman P J, Aalberse R C, ReerinckBrongers $\mathrm{E}$ E. Immunofluorescence studies on renal tissue $Z$ tonsils, adenoids, nasal polyps, and skin of atopic and nono atopic patients with special reference to IgE. Clin Immunod Immunopathol 1975; 4: 392-404.

13 Mizushima Y, Shoji Y, Hoski K, Kiyokawa S. Detection an clinical significance of $\mathrm{IgE}$ rheumatoid factor. $J$ Rheumgsot 1984; 11: 22-6.

14 Floyd M, Tesar J. The role of IgM rheumatoid factoripo experimental immune vasculitis. Clin Exp Immunol 1979: $167-74$.

15 Stevens W J, Verhelst J A, De Clerck L S, Bridts C Grasspollen specific IgG in circulating immune complexes o£ asthma/rhinitis patients. Absence of mononuclear cell activa응 tion [Abstract]. J Allergy Clin Immunol 1984: 73: 156.

16 Nawata $Y$, Koike T, Yanagisawa T, et al. Anti-IgE auto® antibody in patients with bronchial asthma. Clin Exp Immuno 1984; 58: 348-56.

17 Williams R C, Griffith R W, Emmons J D. Field R C. Naturall, occurring human antiglobulins with specificity for IgE. J Clin Invest 1972; 51: 955-63.

18 Yang W H, Dorval G, Osterland C K, Gilmore N J. Circulating immune complexes during immunotherapy. J Allergy Clit Immunol 1979; 63: 300-7.

19 Śpiegelberg H L, Melewicz F M. Fc receptors specific for IgE on subpopulations of human lymphocytes and monocytes. Clint Immunol Immunopathol 1980: 15: 424-33.

20 Eady R A. The mast cell in diseases of the skin. In: Pepys J Edwards A M. eds. The mast cell. London: Pitman Medicalo 1979: 544-9.

21 Althreya B H, Moser G, Schumacher H R. Hanson V. Dahms $B$, Thompson D M. Role $\mathrm{O}$ basophils and mast cells in juvenile rheumatoid arthritis. In: Pepys J, Edwards A M. eds. The mast cell. London: Pitman Medical, 1979: 127-36.

22 Norn S, Skov P S, Geisler A, Klysner R, Permin H. The mast cell and cyclic nucleotide regulation. Histamine release in rheumatoid arthritis and cystic fibrosis. In: Pepys J, Edward A M, eds. The mast cell. London: Pitman Medical, 1979: 53-60 23 Rapaport R J, Kozin F, Mackel S E. Jordon R E. Cutaneous vascular immunofluorescence in rheumatoid arthritis. $A m$ bo Med 1980; 68: 325-31.

24 Deicher H. Mielke H, Daniel W, et al. Studies on the vasculopathy of rheumatoid arthritis and its relation to "systemic rheumatoid disease'. In: Deicher H, Schulz L C. eds. Arthritis: models and mechanisms. New York: Springer, 1981: 118-34유 
25 Ullman S. Hoier-Madson M, Halberg P. Jans H. Sylvest J. Deposits of immunoglobulins and complement in skin of patients with rhcumatoid arthritis. Scand J Rheumatol 1979; 8: 119-23.

26 Conn D L. Schrocter A L, McDuffic F C. Cutaneous vessel immune deposits in rheumatoid arthritis. Arthritis Rheum 1976; 19: 1520 .

27 Tuma S N, Llach F. Sostrin S. Dubois E L, Massry S G. Glomerular IgE deposits in patients with lupus nephritis. Am J Nephrol 1981; 1: 316.
28 McPhaul J J, Newcomb R W, Mullins J D, Thompson A L, Lordon R E. Rogers P W. Participation of immunoglobulin E (IgE) in immune mediated glomerulonephritis. Kidney Int 1974; 5: 2929.

29 Roy L P. Westberg H G, Michael A F. Nephrotic syndrome: no evidence for a role for IgE. Clin Exp Immunol 1973: 13: 5539.

30 Asghar S S. Faber W R. Cormane R H. Clq precipitin in the sera of patients with allergic vasculitis (Gourgerot Ruiter syndrome). J Invest Dermatol 1975; 64: 113-8.

31 Parish W E. Cutaneous vasculitis. In: Wolff H H, Winkelmann R K, eds. Vasculitis. London: Lloyd Luke, 1980: 153-69.

\section{Book review}

Drug Therapy in Rheumatology. Ed. Sanford H Roth. Pp. 239. £23.50. PSG Publishing Company: Littleton, Massachusetts. 1985.

This text aims to provide a structured, organised guide to the use of drugs for the treatment of rheumatic disorders. The book comprises five chapters by different authors. The longest (66 pages) by Dr Calabro is an excellent, well illustrated review of the diagnosis and management of juvenile rheumatoid arthritis and the seronegative spondyloarthropathies. The other chapters include an extensive review of the pharmacology of antirheumatic drugs and a very readable introduction reviewing the various forms of rheumatic diseases and the possible factors such as HLE typing that may affect treatment. Dr Huskisson, the only English author, provides a sound practical framework on which to base drug prescribing for patients. These four chapters are then used in the final chapter as a basis for an orderly approach to treatment.

The editor stresses 'that answers sought for effective pharmacotherapy of the major rheumatic diseases will not be found quickly and simply' in this book and it is certainly not a glorified formulary for quick reference.

Although orientated to the American reader, this book is recommended reading to those rheumatologists who are seeking a more rational approach to prescribing for their patients, and to the members of the pharmaceutical industry who produce the drugs themselves.

Consultant in Rheumatology

J R JENNER

Addenbrooke's Hospital,

Cambridge. 